\title{
Metabolic and Hemodynamic Results and Early Complications in Simultaneous Bilateral versus Unilateral Hip Arthroscopy
}

\author{
Bernardo Aguilera-Bohórquez, MD, Mauricio Pachón, MD*, Miguel Sánchez, MD ${ }^{\dagger}$, \\ Orlando Ramos-Cardozo, $\mathrm{MD}^{\dagger}$, Erika Cantor, $\mathrm{MSc}^{\ddagger}$ \\ Orthopedics and Traumatology-Hip Preservation Unit, Institute of Osteoarticular Diseases, Centro Médico Imbanaco, Cali, \\ ${ }^{*}$ Department of Anesthesiology, Centro Médico Imbanaco, Cali, \\ ${ }^{\dagger}$ Hip Preservation Unit, Institute of Osteoarticular Diseases, Centro Médico Imbanaco, Pontificia Universidad Javeriana de Cali, Cali, \\ ${ }^{\ddagger}$ Research Institute, Centro Médico Imbanaco, Cali, Colombia
}

Background: To compare the hemodynamic parameters-electrolyte concentration, D-dimer level, creatine phosphokinase level—and the incidence of early complications of simultaneous bilateral versus unilateral hip arthroscopy.

Methods: A prospective study was conducted on patients (> 18 years of age) undergoing unilateral or bilateral hip arthroscopy under the same anesthetic between 2013 and 2015. Patients were followed up for 30 days after surgery. In all cases, data were collected before, during, and after the surgical procedure.

Results: One hundred cases of hip arthroscopy (51 unilateral and 49 bilateral) were included in this study. There was a greater variation in systolic blood pressure and heart rate in the unilateral group. The sodium levels were higher in the bilateral group with an adjusted mean difference of $5.31 \mathrm{mmol} / \mathrm{L}(p<0.001)$. During the first 24 hours after the procedure, the proportion of patients with an altered D-dimer of $>500 \mathrm{ng} / \mathrm{mL}$ was $85.7 \%$ in the bilateral group and $56.9 \%$ in the unilateral group. There was no significant difference in the incidence of complications between the groups (bilateral, 8.2\%; unilateral, 9.8\%; crude odds ratio, 0.83; $95 \%$ confidence interval, 0.24 to $2.92 ; p=0.526$ ).

Conclusions: The variations of hemodynamic parameters in patients undergoing hip arthroscopy remained within normal ranges. The findings of this study suggest that bilateral hip arthroscopy be selected according to the patient's condition, considering that the risk of complications and metabolic alterations in bilateral hip arthroplasty are similar to those in unilateral arthroscopy.

Keywords: Hip, Arthroscopy, Femoroacetabular impingement, Complications

Hip arthroscopy is a rapidly evolving surgical procedure indicated for the diagnosis and treatment of hip pathologies, such as labral tears, loose bodies, and femoroacetabular impingement (FAI). ${ }^{1)}$ Portal standardization, adequate

Received February 25, 2019; Accepted April 11, 2019

Correspondence to: Bernardo Aguilera-Bohórquez, MD

Orthopedics and Traumatology-Hip Preservation Unit, Institute of Osteoarticular Diseases, Centro Médico Imbanaco, Carrera 38A, № 5A-100 Tower A Office 706, Cali 760042, Colombia

Tel: +57-3155268429, Fax: +57-25146015

E-mail: baguilera@imbanaco.com.co fluid management, traction time reduction, and, especially, the art of positioning of the patient on the operating table, have reduced the incidence of main complications in the first postoperative year to $1.74 \%{ }^{2,3)}$

There are many controversies surrounding the pathogenesis of FAI. Flattening or convexity of the femoral head-neck junction is partially attributed to genetic and developmental factors. ${ }^{4)}$ Many patients with bony prominences have an elevated risk of developing the same deformity with damage equal or greater in the contralateral hip, although in most cases it remains asymptomatic. ${ }^{5,6}$ Some patients present with alterations and symptoms in 
Aguilera-Bohórquez et al. Metabolic and Hemodynamic Parameters

Clinics in Orthopedic Surgery • Vol. 11, No. 4, $2019 \bullet$ www.ecios.org

both hips simultaneously. Thus, some surgeons favor an early intervention that consists of the detection and early treatment of patients with bilateral clamping to prevent or delay degenerative changes to the hip. ${ }^{7,8)}$ However, there is concern regarding the presumed increase in complications in hip arthroscopies performed bilaterally, although it has not been substantiated by evidence. ${ }^{9,10)}$

Furthermore, elevations in the levels of $\mathrm{D}$-dimer and creatine phosphokinase (CPK) have been found 7 days after postoperative care, which is related to continuous traction and compression of the lower limbs after hip arthroscopy. ${ }^{11)}$ Measurement of D-dimer is important to determine presence of any change in fibrin degradation and the process of any ischemic diseases. ${ }^{12,13)}$ Additionally, measurement of the CPK level is useful in the diagnosis and follow-up of myopathies of any kind, even though CPK is considered a non-specific enzyme. ${ }^{14)}$ Hip arthroscopy differs from arthroscopies of other joints because of the use of infusion pumps that require a constant pressure of 40-80 mmHg for characteristics of the joint and the joint space that need to be reached. ${ }^{11)}$ Additionally, extensive capsulotomies lead to greater edemas of the surrounding tissues and to systemic fluid absorption that can result in changes in serum electrolytes, such as sodium $(\mathrm{Na}+)$, potassium $(\mathrm{K}+)$, and chloride (Cl-).

The purpose of this study was to compare the hemodynamic parameters-electrolyte concentration, Ddimer level, CPK level-and the incidence of early complications between patients undergoing simultaneous bilateral arthroscopy and those undergoing unilateral hip arthroscopy. We hypothesized that there would be no differences in hemodynamic metabolic parameters and in the incidence of complications between bilateral and unilateral arthroscopies.

\section{METHODS}

A prospective study was conducted between 2013 and 2015. Patients older than 18 years with a diagnosis of symptomatic FAI and undergoing unilateral or bilateral hip arthroscopy under the same anesthetic were included. The indications for arthroscopy included hip pain and radiographical signs of impingement. The diagnosis of FAI was based on clinical data, the flexion-adduction-internal rotation test, and morphologic alterations (cam or pincer) on radiographs or magnetic resonance imaging scans or both. The patients who underwent bilateral arthroscopy had pain and radiographic signs in both hips. Patients with laboratory test results outside the reference range were excluded during the preanesthetic assessment. During the study period, 51 patients had indications for bilateral hip arthroscopy, but two patients were excluded because they had abnormal results in preanesthetic laboratory tests. Of 52 patients who had unilateral arthroscopy, one patient was excluded for the same reason. Finally, 51 unilateral and 49 bilateral cases were analyzed. All procedures were performed by the same surgeon (BAB).

If a patient had bilateral symptoms, we suggested simultaneous bilateral surgery and asked the patient to decide between simultaneous and two-stage surgery. This was for the patient to have the option to return to daily activities earlier because patients should only follow a single postoperative rehabilitation program. This study was approved by the Ethics Committee of the Institutional Review Board of Centro Médico Imbanaco (CEI-202, No. IRB00008539) and all participants signed a consent form to participate in the study.

\section{Surgical Procedure}

Before the procedure, all patients were evaluated clinically with provocation maneuvers (flexion, abduction, and internal rotation) and radiologically. The surgical procedure was performed under combined anesthesia (spinal and general anesthesia) with infiltration of the affected area with local anesthetics. Foam boots were used to protect the ankles, and the traction post was covered with a circular foam or perineal protector. The procedure was performed with the patient in the supine position on a traction orthopedic table (Maquet, Rastatt, Germany).

The hip joint was accessed through the standard arthroscopic portals. According to the pathology, either the inside-outside or outside-inside technique was used to access the joint. The acetabular segment was initially worked, and then the femoral segment, after removal of the traction and the perineal post. In some cases, it was necessary for management of the posterior compartment, mainly for the release of the sciatic nerve. In patients with simultaneous bilateral management, traction was removed from the feet and surgical field, and then the second procedure was performed on the contralateral hip according to the surgical plan.

\section{Assessment}

Patients were followed up for 30 days. In all cases, followup data were collected before, during, and after surgery.

\section{Preoperative}

The demographic and clinical data included in this study were age, sex, and cause of intervention. Measurements of serum $\mathrm{Cl}-, \mathrm{K}+$, and $\mathrm{Na}+$ levels were obtained from each 
Aguilera-Bohórquez et al. Metabolic and Hemodynamic Parameters

Clinics in Orthopedic Surgery • Vol. 11, No. 4, $2019 \bullet$ www.ecios.org

patient one hour before surgery. Diastolic blood pressure (DBP), systolic blood pressure (SBP), heart rate (HR), oxygen saturation $\left(\mathrm{SaO}_{2}\right)$, and body temperature were measured at the beginning of anesthesia.

\section{Intraoperative}

After the induction of the combined anesthesia, a twohour monitoring was performed; at the end of the procedure, the $\mathrm{DPB}, \mathrm{SBP}, \mathrm{HR}, \mathrm{SaO}_{2}$, and body temperature were assessed under the effects of the anesthesia. The traction time, surgery time, and intraoperative complications were documented.

\section{Postoperative}

Postoperative follow-up of the patients was performed 24 hours after surgery to control the levels of $\mathrm{Cl}-, \mathrm{K}+$, and $\mathrm{Na}+$. Measurement of D-dimer and CPK was performed. At 30 days after surgery, a clinical examination was performed to assess the occurrence of early complications associated with the procedure ${ }^{15)}$ All complications evaluated are described in Table 1.

\section{Statistical Analysis}

The power of this sample to find a difference of at least $50 \%$ in the increase of $\mathrm{D}$-dimer in patients with bilateral procedures was greater than $90 \%$. The data are summarized by central tendency (mean or median) and dispersion (standard deviation or interquartile range [IQR]) for quantitative variables. The qualitative variables are described as frequency and percentage.

The Student $t$-test or nonparametric Wilcoxon test for paired data was used to compare the $\mathrm{Cl}-, \mathrm{K}+$, and $\mathrm{Na}+$ levels according to the type of surgery. The DBP, SBP, HR, and $\mathrm{SaO}_{2}$ were compared using the repeated-measures analysis of variance or the Friedman test according to the normality criteria. The adjustment to the normality distribution was assessed with the Shapiro-Wilk test. A linear mixed model adjusted for age, sex, surgery time, and trac-

$\begin{aligned} & \text { Table 1. Description of the Complications Evaluated during Data } \\
& \text { Collection }\end{aligned}$
$\begin{array}{cl}\text { Intraoperative complication } & \begin{array}{c}\text { Early postoperative } \\
\text { complication }\end{array} \\
\text { - Injury to the acetabular labrum } & \text { - Infection } \\
\text { and articular cartilage } & \text { - Deep vein thrombosis } \\
\text { - Injury to the lateral femoral } & \text { - Pulmonary thromboembolism } \\
\text { cutaneous nerve anterolaterally } & \\
\text { - Injury secondary to traction: } \\
\text { neurapraxia of the femoral, sciatic, } \\
\text { or peroneal nerve }\end{array}$
- Fluid extravasation

tion time was used to compare the variation of the parameters evaluated according to the type of surgery (unilateral or bilateral arthroscopy). All statistical analyses were done using R.3.3.3 (R Foundation for Statistical Computing, Vienna, Austria) with the "NLME" package. The $p$-values $<0.05$ were considered statistically significant.

\section{RESULTS}

We included 51 unilateral hip arthroscopies and 49 bilateral arthroscopies performed by the same surgeon (BAB). Significant differences were found in age and sex between the groups $(p<0.05)$. The mean age of the unilateral group was 9 years higher than that of the bilateral group. Mixed FAI occurred more frequently in the bilateral group than in the unilateral group. The median traction time was 48 minutes for the unilateral group and 59 minutes for the bilateral group. The median operative time in the bilateral group was 300 minutes (Table 2).

\section{Hemodynamic and Metabolic Parameters}

Statistically significant differences were observed in preoperative and postoperative $\mathrm{Na}+$ levels between groups; greater changes were found in the bilateral group (adjusted mean difference, $5.31 \mathrm{mmol} / \mathrm{L} ; p<0.001)$. K+ levels changed significantly between the preoperative and postoperative period in the unilateral group $(p<0.001)$ and no significant changes were observed in the bilateral group.

Table 2. Patient Demographics and Preoperative Clinical Characteristics

\begin{tabular}{lccr}
\multicolumn{1}{c}{ Variable } & Unilateral $(n=51)$ & Bilateral $(n=49)$ & $p$-value \\
\hline Age $(y r)$ & $50.7 \pm 13.8$ & $40.8 \pm 12.6$ & 0.001 \\
Sex & & & $<0.001$ \\
\hline Female & $45(88.2)$ & $23(46.9)$ & \\
Male & $6(11.8)$ & $26(53.1)$ & \\
\hline Diagnosis & & & \\
\hline cam FAl & $7(13.7)$ & $9(18.4)$ & \\
\hline Pincer FAl & $14(27.5)$ & $1(2.0)$ & \\
\hline Mixed FAl & $30(58.8)$ & $39(79.6)$ & - \\
\hline Traction time (min) & $48.0(25.0-60.0)$ & $59.0(40.0-74.5)$ & - \\
\hline Surgical time (min) & $195.0(180.0-240.0)$ & $300.0(180.0-367.5)$ & - \\
\hline
\end{tabular}

Values are presented as mean \pm standard deviation, number (\%), or median (interquartile range).

FAl: femoroacetabular impingement. 
Aguilera-Bohórquez et al. Metabolic and Hemodynamic Parameters

Clinics in Orthopedic Surgery • Vol. 11, No. 4, $2019 \bullet$ www.ecios.org

No statistically significant differences were found in the level of $\mathrm{Cl}$ - in both groups (Table 3).

DBP did not change significantly during surgery $(p$ $>0.05$ ) (Table 4). However, in the unilateral group, significant changes were observed in the SBP levels $(p=0.001)$. The differences between the initial and final SBP were significant between the unilateral and bilateral groups (adjusted mean difference, $8.69 \mathrm{mmHg} ; p=0.018$ ). These differences were not significant at 2 hours intraoperatively. There was a decrease of SBP values with the increase of traction time $(\beta=-0.117, p=0.020)$. The initial HR was higher in the bilateral group $(p<0.05)$. There were statistically significant changes in HR during surgery in both groups. A greater change was observed between the initial and final HR in the unilateral group (adjusted mean difference, $7.36 \mathrm{mmHg} ;=0.004$ ). These differences were not significant at 2 hours intraoperatively.

There were statistically significant differences in the variation of $\mathrm{SaO}_{2}$ and temperature during surgery between the groups. The differences in the changes in $\mathrm{SaO}_{2}$ at 2 hours intraoperatively were greater in the unilateral group (adjusted mean difference, $0.76 \mathrm{mmHg} ; p=0.032$ ). After the intervention, D-dimer values were higher in the bilateral group with a mean difference of $204.3(p<0.001)$. The proportion of patients with a D-dimer level of $>500$ $\mathrm{ng} / \mathrm{mL}$ was $85.7 \%$ in the bilateral group and $56.9 \%$ in the unilateral group (Fig. 1). The CPK level was lower in the bilateral group with a median of $567.0 \mathrm{ng} / \mathrm{mL}$ (IQR, 320.2 to $1,071.5 \mathrm{ng} / \mathrm{mL}$ ) than that in the unilateral group with a mean of $644.0 \mathrm{ng} / \mathrm{mL}$ (IQR, 401.0 to $1035.0 \mathrm{ng} / \mathrm{mL}$ ); however, these differences were not statistically significant $(p=$ 0.080).

\section{Complications}

The incidence of complications was $9 \%$ without significant differences between the groups (bilateral group, 8.2\%; unilateral group, $9.8 \%$; crude odds ratio, $0.83 ; 95 \%$ confidence interval, 0.24 to $2.92 ; p=0.526$ ). In the unilateral group, there were two cases of pudendal neuropraxia related to traction, two cases of alteration of the femoral cutaneous nerve, and only one case of extravasation of liquid into the abdominal cavity. In the bilateral group, there were three cases of alteration of the lateral femoral cutaneous nerve and one case of superficial infection of the anterior portal. No patient in the bilateral group had complications associated with traction. Cases with femoral cutaneous nerve injury required nerve blocks, and recovery occurred three months later. Wound infections were treated satisfactorily.

\section{DISCUSSION}

In the present study, we compared the vital sign measurements and levels of $\mathrm{Na}+$, chlorine, $\mathrm{K}+, \mathrm{D}$-dimer, and $\mathrm{CPK}$ in patients with unilateral hip arthroscopy and those with bilateral hip arthroscopy. Until now, there have been no other published studies in the literature that evaluate the changes in electrolyte levels and hemodynamic parameters in unilateral and bilateral hip arthroscopies performed un-

\section{Table 3. Comparison of Metabolic Characteristics by Type of Arthroscopy before and after the Intervention}

\begin{tabular}{|c|c|c|c|c|c|c|c|}
\hline \multirow{2}{*}{ Variable } & \multicolumn{3}{|c|}{ Unilateral } & \multicolumn{3}{|c|}{ Bilateral } & \multirow{2}{*}{$\begin{array}{c}\begin{array}{c}\text { Unilateral vs. } \\
\text { bilateral* }\end{array} \\
\text { p-value }\end{array}$} \\
\hline & Initial & Final & $p$-value & Initial & Final & $p$-value & \\
\hline Sodium (mmol/L) & & & 0.001 & & & $<0.001$ & $<0.001$ \\
\hline Median (IOR) & 140.4 (139.8-142.0) & 139.5 (138.1-141.0) & & $139.0(137.0-140.0)$ & $141.0(139.0-146.0)$ & & \\
\hline Mean \pm SD & $140.7 \pm 2.5$ & $139.6 \pm 2.0$ & & $139.2 \pm 5.4$ & $143.9 \pm 7.3$ & & \\
\hline Chlorine (mmol/L) & & & 0.572 & & & 0.218 & 0.259 \\
\hline Median (IOR) & $102.0(100.0-105.0)$ & $103.0(102.0-104.0)$ & & $102.0(100.0-105.0)$ & $102.5(100.7-105.0)$ & & \\
\hline Mean \pm SD & $102.9 \pm 3.2$ & $102.9 \pm 2.0$ & & $102.2 \pm 4.2$ & $103.1 \pm 4.1$ & & \\
\hline Potassium (mmol/L) & & & $<0.001$ & & & 0.283 & 0.010 \\
\hline Median (IQR) & $3.9(3.8-4.1)$ & $4.1(3.9-4.4)$ & & $4.1(3.7-4.3)$ & $4.2(3.7-4.3)$ & & \\
\hline Mean \pm SD & $3.9 \pm 0.4$ & $4.2 \pm 0.4$ & & $3.9 \pm 0.4$ & $4.0 \pm 0.5$ & & \\
\hline
\end{tabular}

IQR: interquartile range, SD: standard deviation.

${ }^{*}$ Adjusted by age, sex, surgery time, and traction time. 
Aguilera-Bohórquez et al. Metabolic and Hemodynamic Parameters

Clinics in Orthopedic Surgery • Vol. 11, No. 4, $2019 \bullet$ www.ecios.org

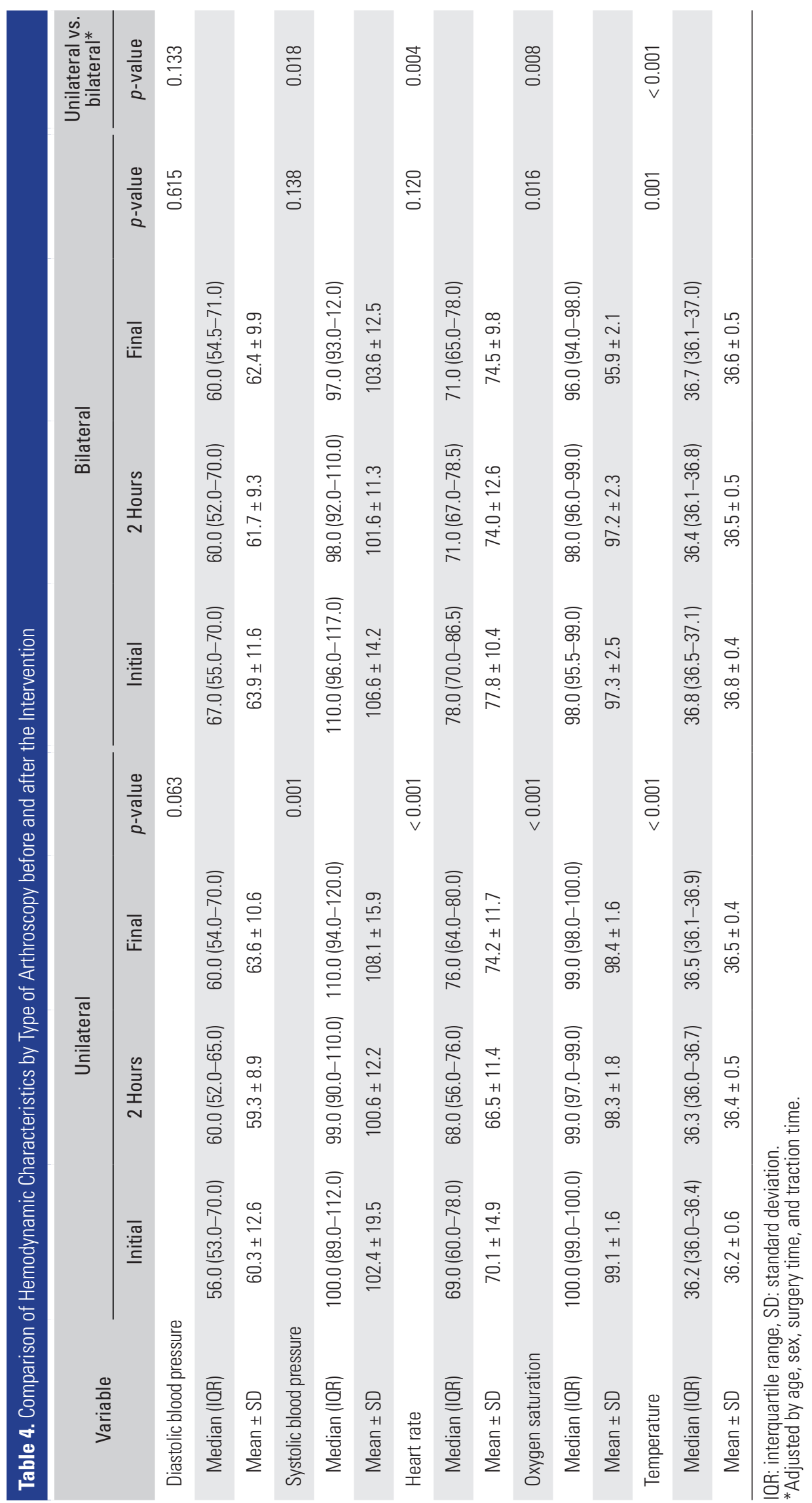


Aguilera-Bohórquez et al. Metabolic and Hemodynamic Parameters

Clinics in Orthopedic Surgery • Vol. 11, No. 4, $2019 \bullet$ www.ecios.org

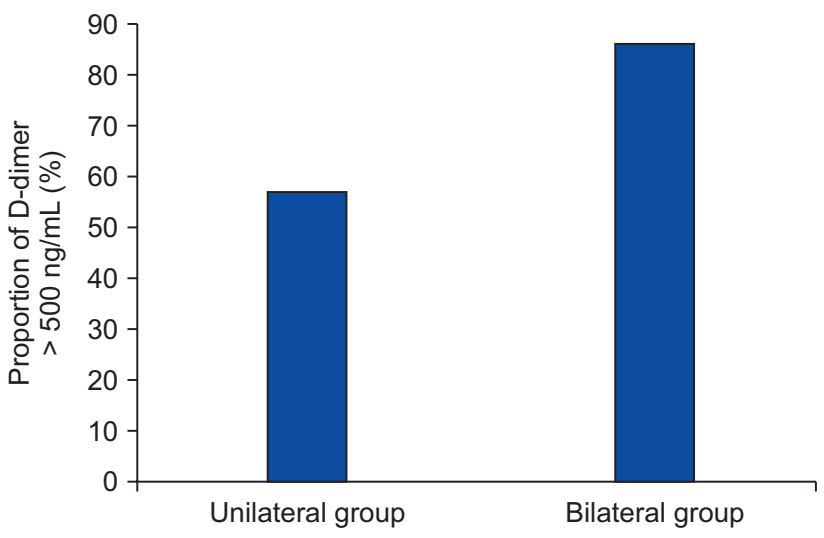

Fig. 1. Percent of D-dimer level $>500 \mathrm{ng} / \mathrm{mL}$ after unilateral and bilateral arthroscopy.

der the same anesthetic. The infusion of liquid substances at high pressure in the hip and adjacent tissues could cause changes in electrolyte levels and hemodynamic parameters, mainly because of the volume of infused liquid substances and systemic absorption in the patient. ${ }^{11,16)}$

In this study, no clinically significant changes were observed in the $\mathrm{Cl}-, \mathrm{Na}+$ and $\mathrm{K}+$ levels according to the type of arthroscopy. An increase in $\mathrm{Na}+$ level was found in the bilateral group, but postoperative $\mathrm{Na}+$ values were within the reference range, ${ }^{17)}$ and the changes in concentration were similar to those reported in unilateral arthroscopies. ${ }^{16)}$ Blood pressure and HR during surgery showed the expected behavior in patients under combined anesthesia. ${ }^{18)}$ Although changes in SBP were observed in the unilateral group, the values were within clinically acceptable limits and similar to those reported in other hip arthroscopies. ${ }^{19)}$ The changes in $\mathrm{HR}, \mathrm{SaO}_{2}$, and body temperature during surgery remained within the established normal ranges. ${ }^{20)}$ The incidence of hypothermia (temperature $<35^{\circ} \mathrm{C}$ ) in this series was $1.0 \%$, which was lower than that reported in the literature $(2.7 \%) .{ }^{21)}$ Low BP and longer surgical time have been associated with the development of hypothermia in hip arthroscopy. ${ }^{21)}$

The behavior of D-dimer in surgical patients has not been studied in depth outside the context of diagnosis of thromboembolic disease. Dindo et al. ${ }^{22}$ found high levels of $\mathrm{D}$-dimer in the postoperative period in surgical patients; the levels did not exceed 1,500 ng/mL for surgical patients with moderate trauma corresponding to the level of tissue injury in hip arthroscopy. ${ }^{21)}$ In this study, we found a significant increase in D-dimer values 24 hours after surgery in patients undergoing bilateral arthroscopy. This difference could be explained by the longer traction time and continuous compression of the lower limbs. The maximum D-dimer level was 2,073 ng/mL and 2,056 ng/mL in unilateral arthroscopy and bilateral arthroscopy, respectively; however, these values were below the $(<3,600 \mathrm{ng} / \mathrm{mL})$ high-risk level of developing deep vein thrombosis after orthopedic surgery. ${ }^{23)}$

The CPK values were above the normal range in both groups, with a slight increase in the unilateral group. Most bilateral procedures were performed using the outside-inside approach that requires a shorter mean traction time than the inside-outside approach used in the unilateral procedures. The enzyme is evidence of muscular trauma to some degree. Although hip arthroscopy is a minimally invasive procedure, it may cause a secondary compromise of muscle mass due to traction and liquid infusion.

The incidence of complications in this study was $9 \%$, higher than that reported in the literature $(0.5 \%-7.5 \%){ }^{2,24)}$ Park et al. ${ }^{25)}$ reported the rate of complications related to traction procedures, surgical technique, and clinical results as $15 \%$. Other studies have found that these types of complications could be related to the learning curve of the surgeon. ${ }^{24)}$ The unilateral group had a predominance of women in a 9:1 ratio. This was attributed, in particular, to the largest proportion of pincer-type FAI cases in this group. In cases with bilateral involvement, the men-towomen ratio was $1: 1$, similar to that reported in recent studies. ${ }^{26)}$

Although it is possible to think that the metabolic alterations caused by bilateral procedures were due to the increase in the volume of infused liquid, longer traction, and surgical time, the results of this study suggest that there are clinically relevant differences in hemodynamic changes, electrolytes, D-dimer, and CPK values that indicate an increased risk of complications in simultaneous bilateral procedures. Both groups showed evidence of similar changes without reaching levels that would suggest a greater risk for the patient. However, it is important to consider that patients in the supine position subjected to traction for a longer period of time tend to produce a greater amount of degradation of metabolites secondary to the surgical injury.

This study has some limitations. First, although the sample size was enough to detect differences in D-dimer values between the two groups, this sample can be considered small to detect differences in other parameters, which may generate a greater probability of a type II error. Nonetheless, this study represents the first attempt to assess the hemodynamic and metabolic changes that occur during bilateral hip arthroscopy. Second, selection bias can be present in this study because of the lack of randomization; however, the effect of potential confounders was 
Aguilera-Bohórquez et al. Metabolic and Hemodynamic Parameters

Clinics in Orthopedic Surgery • Vol. 11, No. 4, $2019 \bullet$ www.ecios.org

controlled for by using multivariate models in the analysis. Third, CPK and D-dimer measurements were obtained 24 hours after surgery to identify initial alterations. However, in the literature, it has been reported that the maximum levels are reached in three days after surgery for the CPK and seven days for the $\mathrm{D}$-dimer. ${ }^{11)}$ This represents a weakness of our research because it is not possible to directly assess the risk of alteration in this group of patients during the period of elevation. It is noteworthy that in our cohort, neither thromboembolic events nor rhabdomyolysis was reported in the first postoperative month.

The variations of hemodynamic parameters and electrolytes in patients undergoing hip arthroscopy remained within normal ranges. The findings of this study suggest that simultaneous bilateral hip arthroscopy can be a viable option according to the patient's condition, considering that the risk of complications and metabolic alterations are similar to those in unilateral arthroscopy.

\section{CONFLICT OF INTEREST}

No potential conflict of interest relevant to this article was reported.

\section{ACKNOWLEDGEMENTS}

We appreciate the Research Institute of Centro Médico Imbanaco for its support during the development of this project.

\section{REFERENCES}

1. Glick JM, Valone F 3rd, Safran MR. Hip arthroscopy: from the beginning to the future: an innovator's perspective. Knee Surg Sports Traumatol Arthrosc. 2014;22(4):714-21.

2. Clarke MT, Arora A, Villar RN. Hip arthroscopy: complications in 1054 cases. Clin Orthop Relat Res. 2003;(406):84-8.

3. Truntzer JN, Hoppe DJ, Shapiro LM, Abrams GD, Safran M. Complication rates for hip arthroscopy are underestimated: a population-based study. Arthroscopy. 2017;33(6):1194201.

4. Pollard TC, Villar RN, Norton MR, et al. Genetic influences in the aetiology of femoroacetabular impingement: a sibling study. J Bone Joint Surg Br. 2010;92(2):209-16.

5. Kang AC, Gooding AJ, Coates MH, Goh TD, Armour P, Rietveld J. Computed tomography assessment of hip joints in asymptomatic individuals in relation to femoroacetabular impingement. Am J Sports Med. 2010;38(6):1160-5.

6. Allen D, Beaule PE, Ramadan O, Doucette S. Prevalence of associated deformities and hip pain in patients with camtype femoroacetabular impingement. J Bone Joint Surg Br. 2009;91(5):589-94.

7. Beck M, Kalhor M, Leunig M, Ganz R. Hip morphology influences the pattern of damage to the acetabular cartilage: femoroacetabular impingement as a cause of early osteoarthritis of the hip. J Bone Joint Surg Br. 2005;87(7):1012-8.

8. Haviv B, O'Donnell J. Arthroscopic treatment for symptomatic bilateral cam-type femoroacetabular impingement. Orthopedics. 2010;33(12):874.

9. Degen RM, Nawabi DH, Fields KG, Wentzel CS, Kelly BT, Coleman SH. Simultaneous versus staged bilateral hip arthroscopy in the treatment of femoroacetabular impinge- ment. Arthroscopy. 2016;32(7):1300-7.

10. Mather RC, Reddy A, Nho SJ. Complications of hip arthroscopy. In: Byrd JW, ed. Operative hip arthroscopy. New York: Springer-Verlag New York; 2012. 403-9.

11. Martin HD, Palmer IJ, Champlin K, Kaiser B, Kelly B, Leunig M. Physiological changes as a result of hip arthroscopy performed with traction. Arthroscopy. 2012;28(10):136572.

12. Hargett CW, Tapson VF. Clinical probability and D-dimer testing: how should we use them in clinical practice? Semin Respir Crit Care Med. 2008;29(1):15-24.

13. Adam SS, Key NS, Greenberg CS. D-dimer antigen: current concepts and future prospects. Blood. 2009;113(13):287887.

14. Morandi L, Angelini C, Prelle A, et al. High plasma creatine kinase: review of the literature and proposal for a diagnostic algorithm. Neurol Sci. 2006;27(5):303-11.

15. Molina CS, Thakore RV, Blumer A, Obremskey WT, Sethi MK. Use of the national surgical quality improvement program in orthopaedic surgery. Clin Orthop Relat Res. 2015;473(5):1574-81.

16. Verhelst L, De Schepper J, Sergeant G, Liekens K, Delport $\mathrm{H}$. Variations in serum electrolyte concentrations and renal function after therapeutic hip arthroscopy: a pilot study. Arthroscopy. 2009;25(4):377-81.

17. Piper GL, Kaplan LJ. Fluid and electrolyte management for the surgical patient. Surg Clin North Am. 2012;92(2):189205.

18. Hug CC Jr, McLeskey CH, Nahrwold ML, et al. Hemody- 
Aguilera-Bohórquez et al. Metabolic and Hemodynamic Parameters

Clinics in Orthopedic Surgery • Vol. 11, No. 4, $2019 \bullet$ www.ecios.org

namic effects of propofol: data from over 25,000 patients. Anesth Analg. 1993;77(4 Suppl):S21-9.

19. Parodi D, Valderrama J, Tobar C, et al. Effect of warmed irrigation solution on core body temperature during hip arthroscopy for femoroacetabular impingement. Arthroscopy. 2014;30(1):36-41.

20. Nakano N, Khanduja V. Complications in hip arthroscopy. Muscles Ligaments Tendons J. 2016;6(3):402-9.

21. Parodi D, Tobar C, Valderrama J, et al. Hip arthroscopy and hypothermia. Arthroscopy. 2012;28(7):924-8.

22. Dindo D, Breitenstein S, Hahnloser D, et al. Kinetics of Ddimer after general surgery. Blood Coagul Fibrinolysis. 2009;20(5):347-52.

23. Sudo A, Wada H, Nobori T, et al. Cut-off values of D-dimer and soluble fibrin for prediction of deep vein thrombosis after orthopaedic surgery. Int J Hematol. 2009;89(5):572-6.

24. Harris JD, McCormick FM, Abrams GD, et al. Complications and reoperations during and after hip arthroscopy: a systematic review of 92 studies and more than 6,000 patients. Arthroscopy. 2013;29(3):589-95.

25. Park MS, Yoon SJ, Kim YJ, Chung WC. Hip arthroscopy for femoroacetabular impingement: the changing nature and severity of associated complications over time. Arthroscopy. 2014;30(8):957-63.

26. Clohisy JC, Baca G, Beaule PE, et al. Descriptive epidemiology of femoroacetabular impingement: a North American cohort of patients undergoing surgery. Am J Sports Med. 2013;41(6):1348-56. 